\title{
RESENHA DE POR QUE É UM LIVRO MÁGICO? DE PEDRO PEREIRA DE LOPES; ANGELINA NEVES. ILUSTRAÇÕES DE MAURICIO NEGRO. MOÇAMBIQUE: ESCOLA PORTUGUESA DE MOÇAMBIQUE / CENTRO DE ENSINO E LÍNGUA PORTUGUESA (EPM-CELP), 2020
}

Regina Michelli

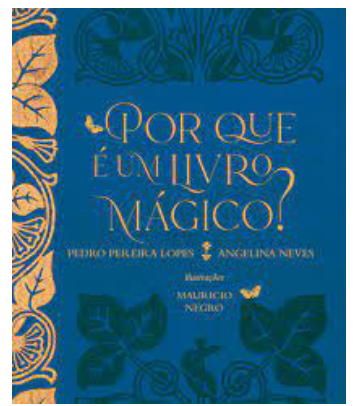

Por que é um livro mágico?, eis a questão!

Ndawina é a personagem principal do livro de Pedro Pereira Lopes e Angelina Neves, com ilustrações de Mauricio Negro. Ela é apresentada por seus gostos: cantar, saltar e correr. Há um porém que movimentará a trama: Ndawina não gostava de ler.

Em consonância com a biografia ao final do livro, Pedro Pereira Lopes nasceu na província da Zambézia e Angelina Neves, em Maputo. Escritores moçambicanos, evidenciam, em sua produção, um compromisso com a infância e com as 
matrizes de seu país na literatura voltada especialmente, mas não exclusivamente, ao público infantojuvenil. O brasileiro Mauricio Negro ilustrou a obra.

Pedro Pereira Lopes escreveu várias obras para a infância e a juventude, destacando-se 0 homem dos 7 cabelos (2012), pela qual recebeu o Prémio Lusofonia, em 2010, e O comboio que andava de chinelos (2019), em que obteve o Prémio Maria Odete de Jesus, em 2016. Em Kanova e o Segredo da Caveira, de 2013, um conto da oralidade é revisitado por Pedro, cuja maestria não se limita a recontar a história, mas oferece a seu leitor um novo desfecho. Há ainda A história do João Gala-Gala, de 2017, em coautoria com o músico Chico António. O escritor evidencia seu talento também em poesia, como se observa em Viagem pelo mundo num grão de pólen e outros poemas, de 2014. O conto "O coração que veio de longe (ou O homem e o líquido)" figura na antologia de Cuentos para leer el mundo, publicado pela Fundação Ajuda em Ação, em Espanha. Envolvido com uma política de incentivo à litura, Pedro Pereira Lopes começou o "Projecto Ler para Ser" em 2015, buscando levar livros para escolas de periferia, sem recursos.

A história de Angelina Neves enraíza-se na Educação, atuando como professora do ensino pré-primário e primário, 
e na literatura, com mais de 50 livros infantis publicados. Personalidade de mérito inquestionável, pioneira na criação e divulgação de obras para a infância e a juventude em Moçambique, no pós-independência, é considerada carinhosamente a "mãe da literatura infantojuvenil moçambicana". Sua ação política como educadora e escritora é marcada pela defesa de várias causas, como o incentivo à leitura e a garantia dos direitos das crianças, desenvolvendo projetos ligados a organizações humanitárias, como a UNICEF, UNESCO e Save the Children. É membro fundadora do Circo da Paz, projeto criado em 1994, cujo objetivo é educar jovens para a paz, por meio das artes. Detentora de vários prêmios, destaca-se o Prêmio PALOP em 2010 para contos tradicionais.

Mauricio Negro é ilustrador e artista gráfico, além de escritor. Sua produção artística aproxima-se de temas com forte apelo a diversidades culturais não eurocêntricas, com relevo às indígenas e africanas, tendo ilustrado obras de vários escritores africanos e afro-brasileiros. Reconhecido internacionalmente, Mauricio Negro recebeu vários prêmios e participou de exposições e catálogos no Brasil e no exterior.

Por que é um livro mágico? atrai a atenção do leitor logo pelo título. Por ser uma pergunta, pressupõe um 
destinatário a quem, de certa forma, desafia a descobrir a magia que reside num livro a ponto de ser adjetivado como tal: "um livro mágico". Mas o que torna um livro mágico? Será esse livro - de Pedro, Angelina e Mauricio - mágico? Se for, por quê?

Enredados na trama inquiridora do título, a próxima etapa de leitura que chama a atenção é a epígrafe: "[os livros são a prova de que os homens podem fazer magia.] palavras do Carl Sagan". Livro e magia são sintagmas que se inter-relacionam e apontam para um fazer humano criador e criativo.

Adentrando a história como se mergulhássemos em seu território de palavras e imagens, encontramos Ndawina: "Esta é a história da Ndawina. A Ndawina gostava de cantar, de saltar e correr mas não gostava de $\operatorname{ler}^{\prime \prime}(2020$, p. 6). A protagonista está distante da magia dos livros, pressuposta pelo título, que não questiona se é mágico, mas por que é um livro mágico. Aparentemente, a associação entre o substantivo e o adjetivo suscita a ideia de algo agradável, benéfico. Uma menina que não gosta de ler fere o constructo inicial do título do livro. Nadwina é apresentada por verbos que indicam atividades mais agitadas, rechaçando aquela que implica maior tranquilidade e um esforço de ordem 
mais intelectual e emocional: ler. A ilustração das duas páginas, 6 e 7, confirma o texto verbal: ela está correndo em meio a uma paisagem em que se combinam plantas, alguns poucos animais e casas ao fundo. Na parede, uma corça parece acompanhar a protagonista, também correndo, indicando agilidade e leveza, pois ambas parecem voar, tal como o canto que igualmente atrai a menina.

A página seguinte introduz novo personagem, o avô, fundamental na trama e responsável por elucidar o mistério do título. A personagem avoenga surge em uma ambiência marcadamente positiva: a menina visitava o avô nos finais de semana, momento provavelmente dedicado ao lazer. Outro dado parece inserir a personagem num espaço de magia: o avô "vivia numa colina onde havia sempre neblina" (2020, p. 9). A neblina não permite uma visão clara de objetos e paisagens, promovendo, de certa forma, o ingresso na imaginação, na interioridade. Por não se enxergar claramente o real, outras imagens mentais podem aflorar à consciência. A ilustração apresenta uma personagem cujos cabelos brancos se confundem com a neblina ao redor da casa, desenhada sobre sua cabeça.

Livro, avô e Ndawina se encontram no presente dele à neta, um embrulho pesado e retangular. Os adjetivos que 
caracterizam a reação da menina expressam seu desgosto por livros: desconfiada, desapontada, descontente, todos caracterizados por prefixo cujo significado é a negação. A imagem evidencia o desconsolo de Ndawina, agachada com o livro nas mãos, sem esboçar o mais tímido sorriso. A ação que se segue coaduna-se ao seu desinteresse pelos livros, pois, simbolicamente, a menina reproduz sua insatisfação, fechando um olho, depois o outro, como se ela se recusasse a ver o livro, o que de fato faz: e, "na sua teima de não gostar de ler, não virou uma página sequer" (2020, p. 13).

A menina explica ao avô a razão de seu desinteresse: na opinião dela, os livros são repetitivos e não trazem novidade alguma ou trazem informações que não atraem a atenção da personagem. O avô, desolado, em reposta à neta afirma que "um livro é um objeto mágico", ao que a menina, brincando, emite a pergunta do título: “- Mágico? Ó avô sabichão, por que é um livro mágico?" (2020, p. 15). Cabe, nesse momento, ao avô explicar e de certa forma convencer neta e leitores da magia capaz de impregnar um livro.

Nas respostas do avô, a poeticidade toma conta da obra, momento de beleza ímpar. Por meio de metáforas, ele delineia o fascínio que uma obra literária provoca. A neta é convidada a imaginar os cenários e as circunstâncias que o 
avô pinta, pois "- Num livro as palavras novas fazem cócegas nos ouvidos" (2020, p. 16).

Imperceptivelmente, a menina começa a interagir com as imagens poéticas criadas pelo avô, interessando-se pela conversa em que ele a induz a descobrir o encantamento que a leitura literária é capaz de promover. Viagens e aventuras, sensibilidade e emoção, personagens e espaços maravilhosos, tudo é possível num livro, que se torna um abrigo, até mesmo para o medo e a solidão. O texto visual, formado por ilustrações com cores vibrantes, interage também artisticamente com as palavras, sugerindo e complementando imageticamente as cenas.

Como um encantador de serpentes, o avô conseguiu abalar as certezas e despertar a curiosidade de Ndawina sobre os livros: "Naquela noite, de mansinho, para que as palavras não desatassem a fugir sozinhas, a Ndawina abriu as páginas do livro de par em par e eram tantas as coisas ali, em uníssono a sussurrar que o livro, num sobressalto, pareceu acordar" (2020, p. 29). Na verdade, quem acorda é Ndawina para o prazer de ler, provavelmente embalada pela ancestralidade presente em barbas e cabelos de neblina.

Para o africano, o ancestral é importante e venerado porque deixa uma herança espiritual sobre a Terra, contribuindo assim para a 
evolução da comunidade ao longo da sua existência. Ele atesta o poder do indivíduo e é tomado como exemplo não apenas para que suas ações sejam imitadas, mas para que cada um de seus descendentes assuma com igual consciência suas responsabilidades. Por força da herança espiritual, o ancestral assegura tanto a estabilidade e a solidariedade do grupo no tempo como sua coesão no espaço. (2011, online)

A narrativa está no cerne da humanidade: o ser humano se compreende e se dá a compreender por meio de histórias em verso e prosa. As que mais despertam a sensibilidade humana são as literárias, as que rearrumam as palavras de forma a retirar os seres humanos de sua cotidianidade automatizante. Igualmente importante para os povos africanos é a tradição oral, a força que reside na palavra. O livro impresso, na obra em análise, recebe o aval do avô, aquele que representa o saber ancestral: é ele quem valida o livro impresso, que será passado à nova geração. É a palavra do avô que acende o interesse da protagonista pelo livro:

O que se encontra por detrás do testemunho, portanto, é o próprio valor do homem que faz o testemunho, o valor da cadeia de transmissão da qual ele faz parte, a fidedignidade das memórias individual e coletiva e o valor atribuído à verdade em uma determinada sociedade. Em suma: 
a ligação entre o homem e a palavra. (HAMPATÉ BÂ, 2010, p. 168)

O livro dado de presente pelo avô a Nadwuina reproduz a mesma capa do livro de Pedro, Angelina e Mauricio: "Era um livro azul com letras douradas na frente" (2020, p. 10). O procedimento narrativo que aqui se apresenta é o da mise-em-abyme, designando, segundo Carlos Reis "a representação de uma ato artístico (uma narrativa, uma peça de teatro, um filme), no decurso de uma história; eventualmente problematizando-a como tal, essa representação interage com a referida história e com o seu desenvolvimento" (2018, p. 265). Na obra, cria-se a ilusão de uma imagem especular na narrativa, que assimila a própria obra que a contém. Associada ao procedimento da mise-em-abyme, outra estratégia de construção da narrativa passível de ser apontada é a metaficção, uma das novas linhas da ficção assinaladas por Teresa Colomer na literatura para crianças e jovens, associada ao humor:

O jogo metaficcional de ensinar as cartas da construção literária, o oferecimento ao leitor de umas folhas em branco que se vão criando de modo simultâneo à sua leitura, esse não permitir a leitura inocente do "Era uma vez" como se se pudesse crer que a história tivesse acontecido prolifera por meio de todo o tipo de artifícios. (2017, p. 221) 
Sobre o conceito de metaficção, Gustavo Bernardo (2010, p. 9) explica: "Trata-se de um fenômeno estético autorreferente através do qual a ficção duplica-se por dentro, falando de si mesma ou contendo a si mesma". A narrativa dos escritores moçambicanos dobra-se sobre o fazer literário, enfatizando o valor da autoconsciência e da autorreflexividade ao suscitar o pensamento crítico sobre o processo de construção narrativo evidenciado na criação de "um livro mágico", que dialoga com a memória literária. Dentre os procedimentos da metaficção, segundo Maria Cecília de Sousa Vieira, encontra-se a mise-emabyme, que pode estender-se também ao texto não-verbal e à materialidade do livro, tanto no projeto gráfico, como no emprego de planos diversos e perspectivas gráficas e mesmo na ilustração. A imagem de Nadwina com o presente que ganhou do avô reproduz a capa do livro em análise: o leitor lê a história da menina e as palavras proferidas pelo avô à neta no livro de título e design gráfico homônimos ao que ela lê.

Assim, retornamos às questões provocadas pelo título: o que torna um livro mágico? Será o livro de Pedro, Angelina e Mauricio mágico? Se for, por quê? Impossível responder de forma absoluta à primeira questão, que incide não apenas nas qualidades do objeto livro e todos os aspectos que o 
conformam em sua materialidade e texto verbo-visual, como no gosto pessoal de cada leitor. Podemos arriscar, porém, que a magia reside especialmente no texto, uma espécie de armadilha que enlaça o leitor quando palavras e imagens ultrapassam a convenção cotidiana da linguagem e se transformam em arte. O livro de Pedro, Angelina e Mauricio atesta essa qualidade: as palavras do avô sobre o livro assinalando experiência e sabedoria - modificam a percepção da neta - representante da nova geração, agitada e ágil -, tal qual o livro dos três autores afeta o leitor. Um contém o outro! A pergunta não se refere a por que o livro é mágico, mas alarga-se à ideia de um livro mágico. Da mesma forma que Nadwina, a protagonista, descobriu o encantamento por ler, nós, leitores, também temos acesso aos atributos elencados pela voz do avô a enumerar a magia de um livro e, sim, este é um livro mágico, não só por afiançar o encantamento que cerca a leitura, como, articulando texto verbo-visual de forma eminentemente artística, abrigar seus leitores, ainda que por alguns momentos, da aridez da vida.

\section{Referências}

BERNARDO, Gustavo. O livro da metafiç̧ão. Rio de Janeiro: Tinta Negra Bazar Editorial, 2010.

COLOMER, Teresa. Introdução à literatura infantil e juvenil atual. São Paulo: Global, 2017. 
HAMPATÉ BÂ, Amadou. A tradição viva. In: KI-ZERBO, Joseph (Ed).

História geral da África, I: metodologia e pré-história da África. 2.ed. rev. Brasília: UNESCO, 2010, p. 167-212.

LOPES, Nei. Ancestral. In: Enciclopédia brasileira da diáspora africana. 4. ed. São Paulo: Selo Negro, 2011. [online]. Disponível em: https://docero. com.br/doc/n5ns01c. Acesso em: 15 set. 2021.

LOPES, Pedro Pereira; NEVES, Angelina. Por que é um livro mágico? Ilustrações de Mauricio Negro. Moçambique: Escola Portuguesa de Moçambique / Centro de Ensino e Língua Portuguesa (EPM-CELP), 2020. REIS, Carlos. Dicionário de estudos narrativos. Coimbra: Almedina, 2018. VIEIRA, Maria Cecília de Sousa. A metafiç̧ão em Mário de Carvalho. 2016. 258f. Tese (Doutoramento em Estudos Portugueses). Universidade Aberta, Portugal, 2016.

\section{Regina Michelli}

Doutora em letras pela Universidade Federal do Rio de Janeiro (UFRJ) e pós doutorado pela Universidade de São Paulo.

Atualmente é professora associada, em regime de dedicação exclusiva, da Universidade do Estado do Rio de Janeiro (UERJ), desenvolvendo atividades docentes na graduação e no PPG em Letras, área de Estudos de Literatura, nas especificidades de Teoria da Literatura e Literatura Comparada, e Literatura Portuguesa, desenvolvendo e orientando pesquisas em Literatura Infantojuvenil e Literatura Portuguesa.

É bolsista PROCIÊNCIA (UERJ/ FAPERJ) desde novembro de 2018.

Líder do Grupo de Pesquisa A narrativa ficcional para crianças e jovens: teorias e práticas, junto ao Diretório de Grupos do CNPq.

Participa do Grupo de Pesquisa DG-CNPq Nós do Insólito: vertentes da ficção, da teoria e da crítica e do Grupo de Trabalho da ANPOLL Vertentes do Insólito Ficcional.

É coordenadora do projeto de extensão Literatura Infantojuvenil: em cont(r)os. 